\title{
Letter
}

\section{Dependence of slope lapse rate over the Greenland ice sheet on background climate}

\begin{abstract}
Near-surface temperature is among the most important external forcings for ice-sheet models studies. It defines where and how much snow and ice is lost from an ice sheet through surface melt. In currently glaciated areas such as Greenland and Antarctica, an increasing number of near-surface temperature measurements are available from automatic weather stations (Steffen and others, 1996; Ahlstrøm and others, 2008; van As and others, 2014). Owing to the fact that ice sheets typically have smooth geometries and large horizontal dimensions, the overlying atmospheric conditions are characterized by smooth near-surface temperature fields, which are, to a great extent, modulated by ice-surface elevation. This enables a spatial interpolation between in situ measurements using an intrinsic linear relation between the surface elevation and near-surface temperature, which is commonly termed a slope lapse rate (here and in the following the slope lapse rate is defined to be positive, if the nearsurface temperature decreases with elevation) (Ritz and others in 1997; Fausto and others in 2009).
\end{abstract}

A slope lapse rate indicates the rate of near-surface temperature decrease with elevation and generally differs from the free-air lapse rate or the rate of moist adiabatic cooling, which is normally within the range of $6-7^{\circ} \mathrm{C} \mathrm{km}^{-1}$ (Marshall and others, 2007; Fausto and others, 2009; Gardner and others, 2009). Analyses of existing observational data in Greenland have shown that slope lapse rates vary significantly through the year, with lower lapse rates recorded over melting glaciers close to the ice-sheet margin (Hanna and others, 2005; Stone and others, 2010). In glacial modeling studies, slope lapse rates (especially over the melting period) play a critical role, and are often used as tunable parameters (e.g. Gardner and others, 2009). The modeling experiments of Stone and others (2010) have demonstrated that an increase in the summer slope lapse rate by $\sim 1.6^{\circ} \mathrm{C} \mathrm{km}^{-1}$ leads to an increase of up to $50 \%$ in the modeled present-day volume of the Greenland ice sheet. The outcomes of stand-alone paleo ice-sheet simulations emphasize an even stronger influence of lapse rates on the modeled volumes of the former ice sheets, which depend strongly on how near-surface temperature forcing is modified during the inception, growth and decay of ice sheets. For example, Abe-Ouchi and others (2007) tested the sensitivity of the former Northern Hemisphere ice sheets to changes in slope lapse rates by $1-$ $2^{\circ} \mathrm{C} \mathrm{km}^{-1}$ and revealed that such changes triggered differences of $50-250 \%$ in the modeled ice volume during the Last Glacial Maximum (LGM). It is therefore important to understand whether the present-day estimates of slope lapse rates from ice-covered regions are appropriate for modeling ice sheets under climate conditions that are different from modern.

Using observational data from four glaciers in the Canadian high Arctic and climate reanalyses, Gardner and others (2009) suggested a negative relation between near-surface lapse rates and lower-troposphere temperatures. Here we seek to extend their analysis to glacial-interglacial timescales by comparing the slope lapse rates that would arise from the two extreme climate states of the last glacial cycle, namely the Holocene and the LGM. For this purpose, we use the outputs of paleoclimate modeling experiments to derive the LGM, early Holocene, and preindustrial climate states and compare our model results with observation-based lapse rates. Our study focuses on the Greenland ice sheet, since it is an ideal target for such an analysis. Although the Greenland ice sheet was more extensive during the glacial period (in many places reaching the continental shelf break), changes in its geometry since the LGM can be considered minor compared with the regions that were entirely buried under continental-scale ice masses during the LGM and had undergone a complete deglaciation during Termination I (O'Brien and others, 1995; Johnsen and others, 1997; Rasmussen and others, 2006). Greenland can therefore serve as a reference region for a nearly one-to-one evaluation of the Holocene and LGM boundary layer conditions over ice-sheet surfaces.

\section{METHODS}

In this study, we analyze three near-surface temperature fields derived from the coupled general circulation model CCSM3 (Community Climate System Model, version 3.0, Collins and others, 2006; Fig. 1). CCSM3 is composed of four separate model components that simultaneously simulate atmosphere, ocean, sea ice and land surface interacting through a central model coupler. For this particular study, the treatment of the atmospheric boundary layer processes in the climate model is of utmost importance. In CCSM3, the turbulence parameterization includes an explicit, non-local atmospheric boundary layer parameterization, while surface exchanges of heat, moisture and momentum are treated with bulk exchange formulations following Monin-Obukhov similarity theory (Collins and others, 2004).

We performed simulations of the pre-industrial, early Holocene and LGM climate conditions with a relatively high atmosphere model resolution of T85, approximately corresponding to $1.4^{\circ}$ and 26 levels in the vertical (Prange and others, 2015). Our pre-industrial and LGM climate simulations follow the protocols established by the Paleoclimate Modelling Intercomparison Project Phase 2 (PMIP2, Braconnot and others, 2007) and share identical setups with the CCSM3 runs presented as part of the PMIP2 (OttoBliesner and others, 2006), but with a twofold increase in the horizontal resolution of the atmosphere and land components. Following this protocol, for the pre-industrial simulation we have applied the greenhouse gas concentrations, ozone and aerosol distributions appropriate for the time before industrialization (ca 1800). The LGM simulation utilizes the orbital parameters, greenhouse gas concentrations, sea-level lowering and the ice-sheet configurations of 21 000 years before present. For the early Holocene simulation, we used the orbital parameters and greenhouse gas concentrations for 8500 years before present $\left(\mathrm{CO}_{2}=260 \mathrm{ppmv}\right.$, $\mathrm{CH}_{4}=660$ ppbv, $\left.\mathrm{N}_{2} \mathrm{O}=260 \mathrm{ppbv}\right)$. All other forcings were 
a
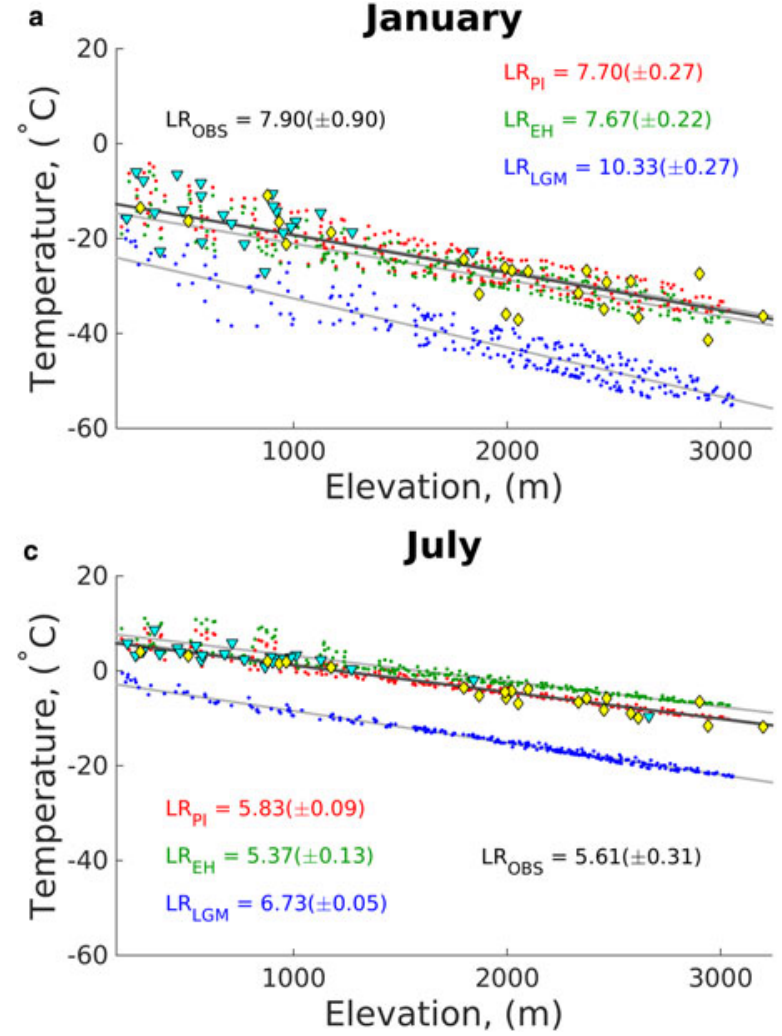

b

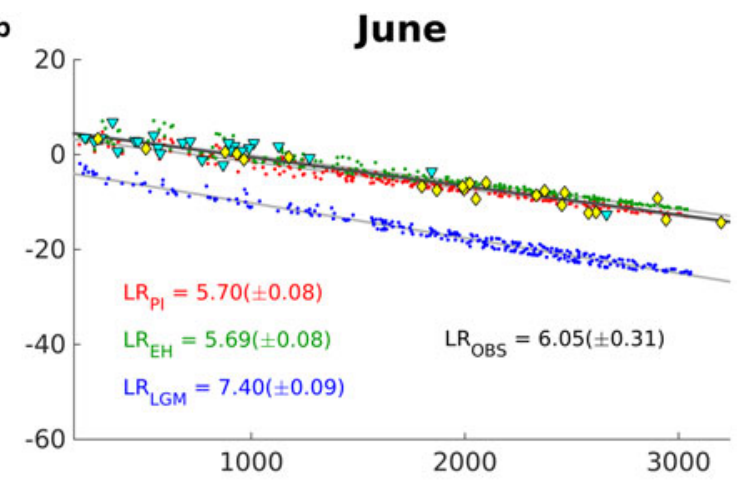

d

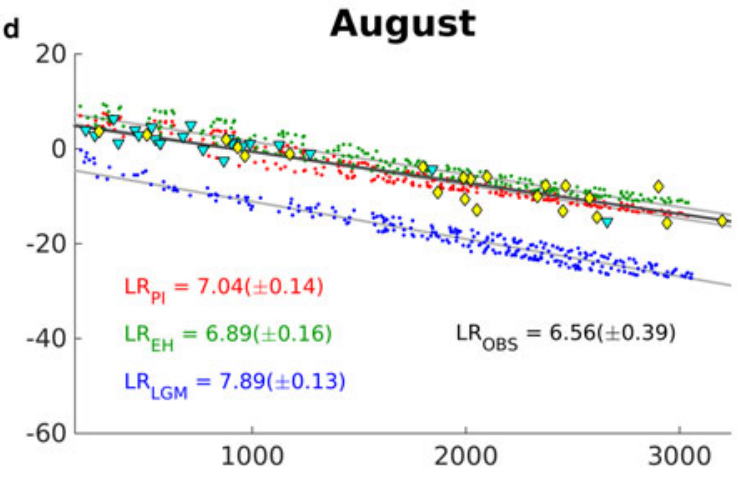

Fig. 1. Modeled near-surface temperatures (vertical axes; ${ }^{\circ} \mathrm{C}$ ) versus surface elevation (horizontal axes), (m), for the coldest month and the melting period derived from the pre-industrial (PI, red), early Holocene (EH, green) and Last Glacial Maximum (LGM, blue) climate simulations. Yellow diamonds and cyan triangles mark the measurements from the GC-Net (Steffen and others, 1996) and PROMICE (Ahlstrøm and others, 2008; van As and others, 2014) stations, respectively. Gray and black lines denote the results of the weighted leastsquares regression for the climate simulations and observations, respectively.

the same as in the pre-industrial simulation. For each simulation, the model has been run over a period of 1400 years to attain a quasi-equilibrium state. 100-year averages of the climate model outputs have been used to infer the monthly slope lapse rates for the LGM, early Holocene and pre-industrial periods (Fig. 2).

A linear relation between near-surface temperatures and ice surface elevation in Greenland has been derived using a $1 / \sigma^{2}$-weighted least-squares regression applied to the mean monthly temperature fields across a range of ice elevations above $500 \mathrm{~m}$ (Fig. 1). Our choice of the lower elevation limit $(500 \mathrm{~m})$ is motivated by the fact that the resolution of the climate model simulations is too low to capture the steep elevation gradients at the ice-sheet margins and may introduce inaccuracies in the modelbased estimates of the slope lapse rate.

The weighting coefficients in the least-squares regression are calculated using the std dev. of temperature for different elevation intervals. Based on these calculations, we determine the slope lapse rates for each month, compared then

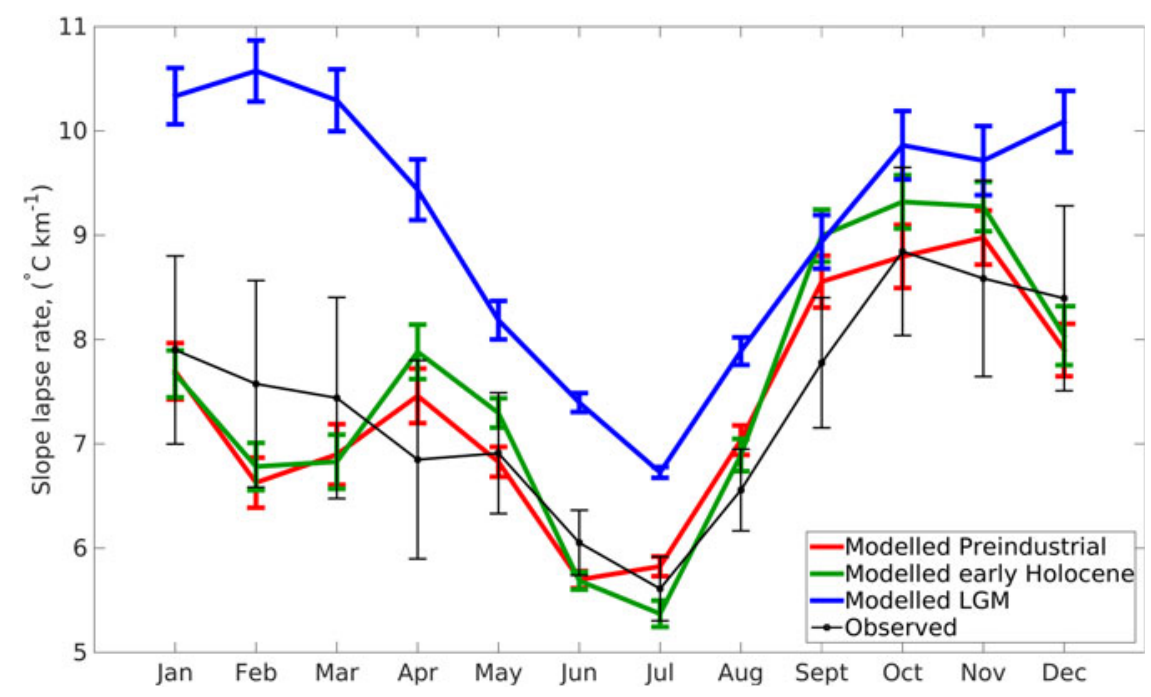

Fig. 2. Evolution of slope lapse rates through the year as inferred from the LGM (blue), the early Holocene (green) and pre-industrial (red) climate simulations and observations (black). Vertical bars mark the corresponding standard errors. 
Table 1. Overview of observational and model-based slope lapse rates

\begin{tabular}{lcc} 
Source & $\begin{array}{c}\text { Mean annual slope } \\
\text { lapse rate }\left({ }^{\circ} \mathrm{C} \mathrm{km}^{-1}\right)\end{array}$ & $\begin{array}{c}\text { Summer slope } \\
\text { lapse rate }\left({ }^{\circ} \mathrm{C} \mathrm{km}^{-1}\right)\end{array}$ \\
\hline Steffen and Box (2001) & 7.1 & 5.1 \\
Hanna and others (2005)* & 8.2 & 7.9 \\
Hanna and others (2005)† & 5.9 & 4.3 \\
Fausto and others (2009) & 6.8 & 5.0 \\
This study, observed & 7.4 & 6.0 \\
This study, pre-industrial & 7.4 & 6.2 \\
This study, early Holocene & 7.5 & 5.9 \\
This study, LGM & 9.1 & 7.3 \\
\hline
\end{tabular}

* High elevations, above $1 \mathrm{~km}$.

+ Low elevations, below $1 \mathrm{~km}$.

with the estimates from available observations taken in Greenland (Table 1; Steffen and others, 1996; Steffen and Box, 2001; Hanna and others, 2005; Ahlstrøm and others, 2008; Fausto and others, 2009). In this study, we combine observational datasets from automated weather stations from the PROMICE (Program for Monitoring of the Greenland ice sheet, Ahlstrøm and others, 2008; van As and others, 2014) and GC-Net (Greenland Climate Network; Steffen and others, 1996) projects to validate our model-based estimates (near-surface temperature and slope lapse rates, see Figs 1, 2). The combined dataset consists of monthly mean temperatures from 24 PROMICE stations mainly located at low elevations (up to $1000 \mathrm{~m}$ ) and operating from year 2007 and mean hourly temperatures from 22 GC-Net AWS stations mostly located between elevations 2000 and $3000 \mathrm{~m}$ and operating since year 1995. The complete list of stations used in this study can be found in Supplementary Tables S1 and S2. Based on these datasets, we have calculated mean monthly temperature over the observational period and have combined them in our slope lapse rate calculations. Our observation-based lapse rates have been estimated following the same procedure as for the model-based estimates.

\section{RESULTS AND DISCUSSION}

The three climate simulations and observational data consistently produce a large scatter in near-surface temperatures at similar elevation levels during the cold months (Fig. 1a). This is contrasted by a relatively minor spread inferred for the warm summer period (Figs $1 \mathrm{~b}-\mathrm{d}$ ). The stronger scattering in the winter temperatures compared with the summer period finds its expression in the higher values of the surface temperature std dev. (Fausto and others, 2011; Rogozhina and Rau, 2014; Seguinot and Rogozhina, 2014; Wake and Marshall, 2015). This is generally attributed to increased cyclonic activity in winter (van As and others, 2014) and a larger climate sensitivity of near-surface air temperature over frozen surfaces than over melting surfaces (Gardner and others, 2009). Due to a smaller scatter and a nearly linear temperature decrease with elevation, constant slope lapse rates appear to describe better the summer near-surface temperatures, which matter most for ice-sheet modeling studies.

In agreement with observations (Steffen and others, 1996; Steffen and Box, 2001; Hanna and others, 2005; Ahlstrøm and others, 2008), our climate simulations of the LGM, early Holocene and pre-industrial periods feature a clear seasonal cycle in the slope lapse rates, with the lowest values occurring in the summer period (Fig. 2). This phenomenon is explained by a complex interplay between several mechanisms such as the summer surface melting at lower elevations, which tends to limit the near-surface warming by keeping the surface temperature at the melting point, and winter boundary layer processes associated with radiative surface cooling, which is weaker at lower elevations, stronger katabatic winds and increased sensible heat flux at lower elevations (Gardner and others, 2009; van As and others, 2014).

The early Holocene and pre-industrial simulations produce comparable temperatures over the Greenland ice sheet, which are contrasted by $10-30{ }^{\circ} \mathrm{C}$ lower nearsurface temperatures during the LGM (Fig. 1). The modeled early Holocene climate in Greenland is characterized by somewhat warmer summers and colder winters compared with the pre-industrial period. However, the modeled early Holocene and pre-industrial near-surface temperatures are both in close agreement with the present-day measurements from automated weather stations (Fig. 1). As a result, the monthly lapse rates derived for the two historical periods and the observational period are also similar (Fig. 2). The estimated lapse rates range from 5.70 to $8.98^{\circ} \mathrm{C} \mathrm{km}^{-1}$ for the pre-industrial period, from 5.37 to $9.32^{\circ} \mathrm{C} \mathrm{km}^{-1}$ for the early Holocene and from 5.61 to $8.59^{\circ} \mathrm{C} \mathrm{km}^{-1}$ for the observational period. The largest differences of $\sim 1.0^{\circ} \mathrm{C} \mathrm{km}^{-1}$ between the lapse rate curves (Fig. 2) are found during the autumn and spring months.

An entirely different picture is presented by the LGM simulation that produces larger slope lapse rates throughout the year. The difference between the LGM and various interglacial lapse rates is smallest in the autumn $\left(0.06-1.16^{\circ} \mathrm{C} \mathrm{km}^{-1}\right)$ and largest during the late winter $\left(\sim 4^{\circ} \mathrm{C} \mathrm{km}^{-1}\right)$. Throughout the surface ablation period, the LGM lapse rates are $0.85-$ $1.71^{\circ} \mathrm{C} \mathrm{km}^{-1}$ above the interglacial values. This inference supports the existence of a previously hypothesized negative relation between the slope lapse rates and lower-troposphere temperatures by Gardner and others (2009). Our finding of higher lapse rates during the LGM indicates that the concept of Gardner and others (2009) may be applicable to periods outside the observational record and over multimillennial timescales.

Interestingly, in line with the results of Kageyama and others (2005) our simulations reveal that LGM free-atmosphere lapse rates increase at low latitudes, but generally decrease in the extratropics. This implies that glacial-interglacial changes in slope lapse rates over Greenland are linked to elevation-dependent boundary layer and surface processes, including summer melting, radiative winter cooling and a non-linear negative relation between surface temperature and inversion strength modifying turbulent heat fluxes (Krinner and Genthon, 1998).

\section{CONCLUSIONS}

We have used the outputs of global climate simulations of the LGM, early Holocene and pre-industrial periods to reveal that slope lapse rates over the Greenland ice sheet may have responded strongly to changes in climate conditions over glacial-interglacial timescales. Our model- and observation-based lapse rate estimates for the early Holocene, preindustrial and observational periods are in close agreement. Hence, it is reasonable to assume that these lapse rates within the range of $\sim 5.5$ and $9.5^{\circ} \mathrm{C} \mathrm{km}^{-1}$ over the seasonal 
cycle are broadly representative of the interglacial climate conditions. In contrast, our estimates of the glacial slope lapse rates obtained from the LGM simulation are up to $4^{\circ} \mathrm{C}$ $\mathrm{km}^{-1}$ higher than the above interglacial values.

Our study indicates that slope lapse rates may have significantly varied with background climate. We suggest that following the transition from the last glacial period to the Holocene interglacial period, the mean annual lapse rates over the Greenland ice sheet decreased by nearly $20 \%$. Although the underlying mechanisms need further investigation, this finding has strong implications for paleoglacial modeling studies, in which lapse rates are assumed to be constant in space and time and are often based on presentday observations.

\section{SUPPLEMENTARY MATERIAL}

The supplementary material for this article can be found at https://doi.org/10.1017/jog.2017.10

\section{CONTRIBUTION STATEMENT}

O.E. performed the analysis and prepared the manuscript draft, I.R. designed the concept and worked on the manuscript text, M.P. provided CCSM3 output data and model description, P.B. and M.P. interpreted the global climate fields; all authors contributed to the data interpretation and writing of this paper.

\section{ACKNOWLEDGEMENTS}

O.E. has been supported by the German Academic Exchange Service (DAAD) grant No. 91578577. I.R., M.P., A.P., P.B. and M.S. have been supported by the BMBF German Climate Modeling Initiative PalMod. J.B. has been supported by Helmholz Graduate School GeoSim. We thank Huadong Liu and INTERDYNAMIC project HydroPaTH for providing the results of the climate model experiments, Konrad Steffen Research Group for providing GC-Net observational data and PROMICE team (data are available at http://www. promice.dk). We are grateful to Jennifer Newall for having copyedited the manuscript.

\section{${ }^{1}$ MARUM - Center for Marine Environmental Sciences, University of Bremen, Germany, ${ }^{2}$ Helmholtz Centre Potsdam GFZ, German Research Centre for Geosciences, Germany, ${ }^{3}$ National Research University, Higher School of Economics, Russia, ${ }^{4}$ Institute of Meteorology, Free University Berlin, Germany}

E-mail: Irina Rogozhina <irogozhina@marum.de>

\section{REFERENCES}

Abe-Ouchi A and Segawa T and Saito F (2007) Climatic conditions for modelling the Northern Hemisphere ice sheets throughout the ice age cycle. Clim. Past, 3(3), 423-438 (doi: 10.5194/cp-3-4232007)
Ahlstrøm AP and PROMICE project team (2008) A new programme for monitoring the mass loss of the Greenland ice sheet. Geol. Surv. Denmark Greenland Bull., 15, 61-64

Braconnot $P$ and 12 others (2007). Results of PMIP2 coupled simulations of the Mid-Holocene and Last Glacial Maximum-Part 1: experiments and large-scale features. Clim. Past, 3(2), 261-277 (doi: 10.5194/cp-3-261-2007)

Collins WD and 9 others (2004) Description of the NCAR Community Atmosphere Model (CAM3). Tech. Rep. NCAR/ TN-464+STR, National Center for Atmospheric Research, Boulder, CO, 214pp.

Collins WD and 10 others (2006) The Community climate system model version 3 (CCSM3). J. Clim., 19(11), 2122-2143 (doi: 10.1175/JCLI3761.1)

Fausto RS, Ahlstrøm AP, Van As D, Bøggild CE and Johnsen SJ (2009) A new present-day temperature parameterization for Greenland. J. Glaciol., 55(189), 95-105 (doi: 10.3189/ 002214309788608985)

Fausto RS, Ahlstrøm AP, Van As D and Steffen K (2011) Present-day temperature standard deviation parameterization for Greenland. J. Glaciol., 57, 1181-1183 (doi: 10.3189/0022143117988 43377)

Gardner AS and 7 others (2009) Near-surface temperature lapse rates over Arctic glaciers and their implications for temperature downscaling. J. Clim., 22(16), 4281-4298 (doi: 10.1175/ 2009JCLI2845.1)

Hanna E and 5 others (2005) Runoff and mass balance of the Greenland ice sheet: 1958-2003. J. Geophys. Res.: Atmosph., 110(D13) (doi: 10.1029/2004JD005641)

Johnsen SJ and 10 others (1997) The $\delta^{18} \mathrm{O}$ record along the Greenland Ice Core Project deep ice core and the problem of possible Eemian climatic instability. J. Geophys. Res.: Oceans, 102(C12), 26397-26410 (doi: 10.1029/97JC00167)

Kageyama M, Harrison SP and Abe-Ouchi A (2005) The depression of tropical snowlines at the last glacial maximum: what can we learn from climate model experiments? Quat. Int., 138, 202-219 (doi: 10.1016/j.quaint.2005.02.013)

Krinner G and Genthon C (1998) GCM simulations of the Last Glacial Maximum surface climate of Greenland and Antarctica. Clim. Dyn., 14(10), 741-758 (doi: 10.1007/s003820050252)

Marshall SJ, Sharp MJ, Burgess DO and Anslow FS (2007) Nearsurface-temperature lapse rates on the Prince of Wales Icefield, Ellesmere Island, Canada: implications for regional downscaling of temperature. Int. J. Climatol., 27(3), 385-398 (doi: 10.1002/ joc.1396)

O'Brien S and 5 others (1995) Complexity of Holocene climate as reconstructed from a Greenland ice core. Science, 270(5244), 1962-1964 (doi: 10.1126/science.270.5244.1962)

Otto-Bliesner BL and 5 others (2006) Last Glacial Maximum and Holocene climate in CCSM3. J. Clim., 19(11), 2526-2544 (doi: 10.1175/JCLI3748.1)

Prange M, Steph S, Liu H, Keigwin LD and Schulz M (2015) Hydroclimatic variability in the Panama Bight Region during Termination 1 and the Holocene. In Integrated analysis of interglacial climate dynamics (INTERDYNAMIC), Schulz $M$ and Paul A (Eds.). Springer, 63-68 (doi: 10.1007/978-3-319-006932_11)

Rasmussen SO and 10 others (2006) A new Greenland ice core chronology for the Last Glacial termination. J. Geophys. Res.: Atmosph. (1984-2012), 111(D6) (doi: 10.1029/2005JD006079)

Ritz C, Fabre A and Letréguilly A (1997) Sensitivity of a Greenland Ice Sheet model to ice flow and ablation parameters: consequences for the evolution through the last climatic cycle. Clim. Dyn., 13(1), 11-23 (doi: 10.1007/s003820050149)

Rogozhina I and Rau D (2014) Vital role of daily temperature variability in surface mass balance parameterizations of the Greenland Ice Sheet. Cryosphere, 8(2), 575-585 (doi: 10.5194/ tc-8-575-2014)

Seguinot J and Rogozhina I (2014) Daily temperature variability predetermined by thermal conditions over ice-sheet surfaces. J. Glaciol., 60(221), 603-605 (doi: 10.3189/2014JoG14J036) 
Steffen K and Box J (2001) Surface climatology of the Greenland ice sheet: Greenland Climate Network 1995-1999. J. Geophys. Res.: Atmosph., 106(D24), 33951-33964 (doi: 10.1029/ 2001JD900161)

Steffen K and Box JE and Abdalati W (1996) Greenland climate network: GC-Net. US Army Cold Regions Reattach and Engineering (CRREL), in CRREL 96-27 Special Report, DTIC Document, 98-103 (doi: 10.1029/2001JD900161)

Stone EJ, Lunt DJ, Rutt IC and Hanna E (2010) Investigating the sensitivity of numerical model simulations of the modern state of the
Greenland ice sheet and its future response to climate change. Cryosphere, 4(3), 397-417 (doi: 10.5194/tc-4-397-2010)

van As D, Fausto RS, Steffen K and PROMICE project team (2014) Katabatic winds and piteraq storms: observations from the Greenland ice sheet. Geol. Surv. Denmark Greenland Bull., 31, 83-86

Wake L and Marshall S (2015) Assessment of current methods of positive degree-day calculation using in situ observations from glaciated regions. J. Glaciol., 61(226), 329-344 (doi: 10.3189/ 2015JoG14J116)

MS received 23 July 2016 and accepted in revised form 13 February 2017; first published online 3 April 2017 